\title{
ПРОБЛЕМЫ И ПЕРСПЕКТИВЫ АКТИВИЗАЦИИ ТУРИЗМА В ЦИФРОВОЙ ЭКОНОМИКЕ
}

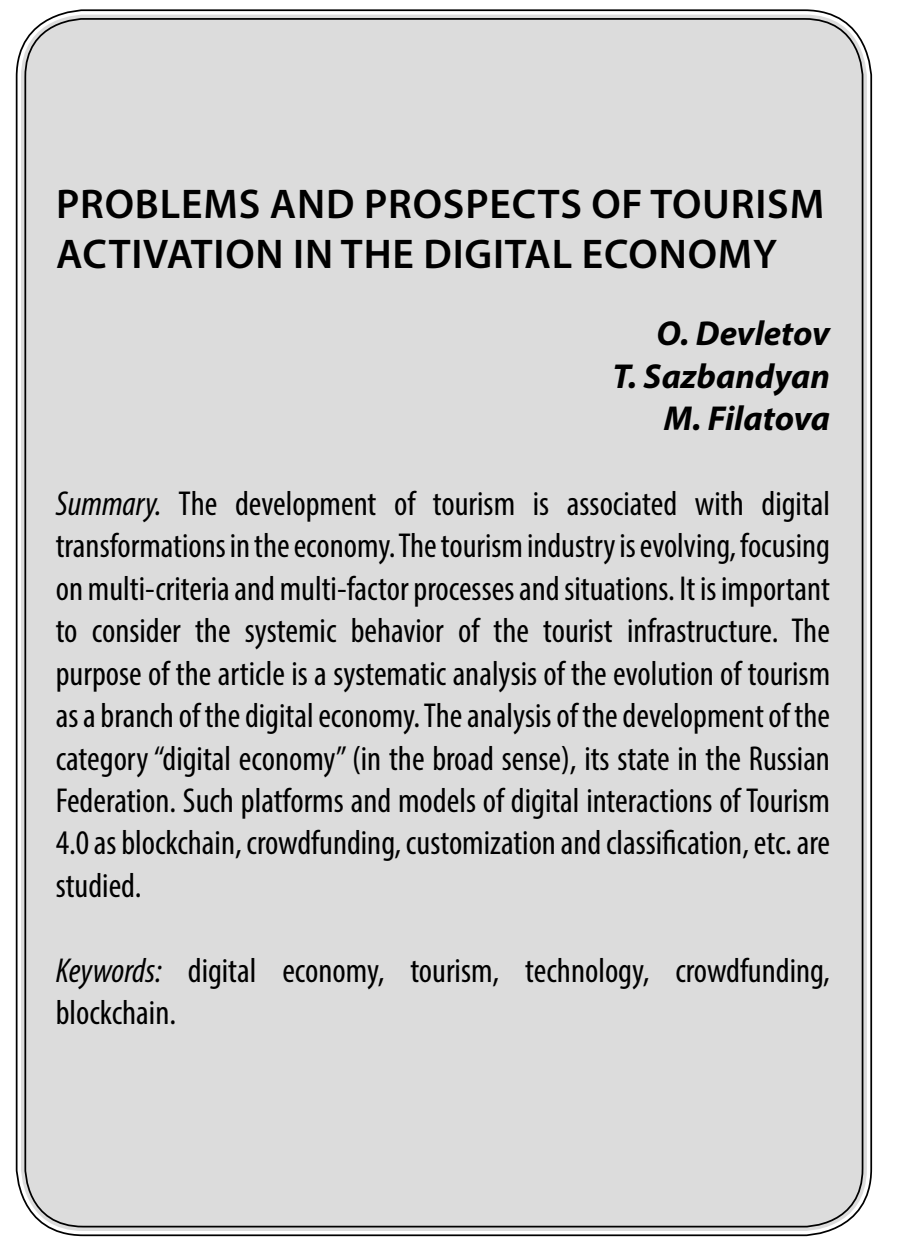

\section{Введение}

ц ифровую экономику понимают в узком (технологическом, потребительском) и широком (инфраструктурном, экосистемном) смысле, включая и loT (Интернет вещей), краудфандинг, Big Data, туманные (Fog) и облачные (Cloud) сервисы, «умные» (SMART) системы и концепцию искусственного интеллекта [1].

Цифровизация инфраструктуры общества, экономики охватывает и обслуживающие сферы, в частности, туристическую индустрию [2-3], обеспечивая в ней и с ней релевантные цифровые взаимодействия, их эволюционный потенциал по расширению аудитории, сервиса, разнообразия (как одного из факторов динамического порядка). Это важно и для инвестиционной привлекательности туристических проектов, регионов, всей индустрии [4].
Девлетов Олег Усманович

ЗМС России, к.и.н., доцент, Институт Экономики и культуры; действительный член Петровской академии наук и искусств по отделению туризма, г. Санкт-Петербург oleg-devletov@mail.ru

Сазбандян Тамара Валерьевна

К.ф.н., дочент, Институт экономики и культуры, член Русского географического общества

tamojan@mail.ru

Филатова Мария Сергеевна

К.ф.н., Институт экономики и культуры; заместитель Генерального директора турагентства, ООО «Фьюче Тревел»; директор по развитию направления HoReCa, OOO «НПК Трейд Групn» moiseeva_m@mail.ru

Аннотация. Развитие туризма связано с цифровыми трансформациями в экономике. Туристическая индустрия эволюционирует, ориентируясь на многокритериальность и многофакторность процессов, ситуаций. Актуально рассматривать системное поведение туристической инфраструктуры. Цель статьи — системный анализ эволюции туризма, как отрасли цифровой экономики. Проведен анализ развития категории «цифровая экономика» (в широком смысле), ее состояние в РФ. Исследованы такие площадки и модели цифровых взаимодействий Туризма 4.0, как блокчейн, краудфандинг, кастомизация и классификация и др.

Ключевые слова: цифровая экономика, туризм, технология, краудфандинг, блокчейн.

Туристическую активность оценивают на макро- или микро-уровне. В системном смысле, туристическая активность - многообразие усилий менеджмента туризма на увеличение основных параметров (например, оборачиваемости, задолженностей, активов и др.). Есть возможность корректировать эволюционную траекторию, адаптироваться к рыночным условиям, есть понимание необходимости инвестировать ресурсы в новейшие инструменты, цифровые платформы и стремления к самоорганизации.

В эпоху цифровой экономики, туризм, туристический бизнес пытается перейти на «крауд-модели», блокчейн-технологии и криптовалютные транзакции. Активизируется партнерский (аффилиантный) маркетинг, основанный на привлечении трафика аффилиатов (партнеров), клиентов. Это осуществляется посредством соцсетей, поддержки PR-акций, портфолио, баз данных 
(клиентов, продуктов, заказов), пополняемых при каждом эффективно выполненном заказе и повышающем комфортность партнерского сотрудничества.

Пандемия уже активировала переход к внутренним и даже виртуальным турам, в период, когда принимающая сторона теряет потенциальных туристов. Спрос на туры - практически нулевой, но авиаперевозчики, отели готовы к «реанимации». Растет интерес к новым технологиям, платформам турпродукции, ее продвижения. Тур-блоги ориентированы на возврат «допандемийных» клиентов.

В РФ разрабатывают шлюз биткойн-блокчейн, улучшается законодательная база, работает спецгруппы Думы и Сколково, Финтех. Эксперты отмечают (пока на основе анализа скачков биткойн) связь биткойн-курса с индексом S\&P500, акциями, долларом США. Если эти связи станут законом, повлияют и на туристический рынок, следует к такой возможности адаптивно подготовиться.

Российский турбизнес, оправляясь от коронавирусных последствий, старается вложиться во внутренний туризм. Для этого должно расти качество, а инфраструктура и поддержка покупателей туров должна расширяться. Особенно, в сфере делового и рекреационного туризма. Российская ассоциация туроператоров старается при этом не завышать цены-2021. У турбизнеса проблем сейчас множество, это и распределение ответственности между операторами, логистиками, отельерами, агентами и другие. Следует привлечь современные веб-площадки, чтобы получить частные («гражданские») кредиты через них, без банков.

Продвигающий внутренний туризм (в частности, российский) турбизнес вложил более \$1 млн. в маркетинг онлайн. Более $30 \%$ россиян стали совершать мобильные транзакции в этой сфере, например, выделяется сеть отелей с каналом бронирования в Инстаграме. Впрочем, туриндустрия не может выделять, как в «допандемийный период», огромный бюджет на продвижение бизнеса, сайтов.

\section{Б^окчейн как эво^юционная техно^Огия и возможность роста разнообразия на рынке туризма}

На целевого клиента турфирмы можно повлиять вдохновением, примерами (фото-видеоотчеты), бронированием («в данной точке, тотчас, с любым гаджетом»), преимуществами новых впечатлений, знаний, получаемыми при поездке.

Согласно статистике Ростуризма, из более 4400 компаний, включенных в Федеральный реестр, на внутрен- ний туризм ориентируется (переориентируется) более 58\%. При этом 51\% предпочитают готовый тур от компании, отмечая в туризме основные революционные тенденции - платформенность, впечатлительность, технологичность и совместность потребления (sharing economy). Последняя изменяет роли поставщиков туристических услуг и сервиса [5] (лаукостеры, отельеры и другие, переходящие к цифровым решениям, паспортам, профилям туристов и туров).

За рубежом активно ведется цифровизация туризма, например, в Шри-Ланке, Индонезии, Камбодже, Вьетнаме объединяются услуги для всех туристов данного азиатского направления.

В РФ развивается туризм внутренний и въездной, событийный (пример - Олимпиада-2014) и рекреационный. Онлайн-продажи немалые, растущие, причем как на полный комплект сервиса (логистика, размещение, экскурсии и др.), так и на часть сервисных предложений. Например, у сервисной площадки Booking.com (вместе с агрегаторами служб такси, досуга и др. [6]), уже ведется планирование туров нейросистемой, самообучающейся и учитывающей поисковые запросы, предпочтения, «средние чеки», экскурсии и др.

Так создается цифровая туристическая экосистема, происходит интеграция цифровых технологий в отрасль, что является важным показателем инновационного развития данной сферы, ведущей к интеллектуальному туризму.

Туркомпании исследуют, тестируют технологии блокчейн для повышения качества и надежности обслуживания. В ближайшие годы блокчейн-цепи организации, проведения и сопровождения туров серьезно повлияют на потребительский сегмент [7].

Bce больше путешественников, открывающих крипто-кошельки для транзакций. На рынок криптовалют выходят не только трейдеры и инвесторы, но и туроператоры. Формируются центры блокчейн-туризма, криптовалютных транзакций. В пандемию, туроператоры стали привлекать возможности мульти-кошельков, это изменит туристическую область. Например, монеты криптовалют (токены) станут правом на турпоездку, накопление «милей». Какая станет самой устойчивой, эффективной - открытый вопрос.

Криптовалютный инфраструктурный инструмент транзакций (сервер, БД, «облака», оборудование, безопасность и др.), поддерживаемый заинтересованными в туризме сторонами, не контролирующими друг друга. Например, туроператоры могут получать оплату биткойнами «внутри» компании (аналогично «биллинговой» 
системе). Монета (токен) или ее часть станет правом на турпоездку.

Власти советуют туркомпаниям «протестировать» вначале блокчейн для борьбы с коррупцией, мошенниками, проверки надежности шлюзов, «обменников». В РФ есть уже статья УК (за «Оборот денежных суррогатов»). Блокчейн может нести и курсовую выгоду туркомпании. Но турбизнес пока не заявил о своих принципиальных устремлениях, а власти пока ограничивать и регулировать их не желают.

Криптовалюта получаема, пересылаема безотзывно (лишь получатель сможет сам вернуть), вывести из системы. Данные транзакций, о владельце - только у владельца. Майнинг, даже «облачный», освобождающий пользователя от настроек, оплаты электроэнергии, владения оборудованием (оно арендуется) - достаточно мучителен для непосвященных, да и завершается процесс уже потихоньку. Другое дело - ICO («первичное размещение токенов, монет»), это инвестиционный (без госрегулирования как в IPO) механизм с продажей токенов, генерируемых разовой (ускоренной) эмиссией. Хотя количество ICO удвоилось, вырос объём привлеченных средств, который измеряется миллионами долларов, для туристической индустрии это пока нераскрытый потенциал.

Цифровые инфраструктуры в туризме позволяют формировать рейтинги доверия, объединяют продавцов-покупателей услуг и товаров едиными платформами, отчетностями, ценообразованием, стандартами качества, системами безопасности [8]. Это формируют, эволюционируют цифровой Туризм 4.0 с принципами:

1. достаточной автоматизации и интеллектуализации;

2. релевантности технологической, инфологической поддержки;

3. максимального единения с ІоT и lloT;

4. поддержки жизненного цикла турпродукта;

5. единых технологий (например, блокчейн);

6. наличия обратных эффективных связей.

Информация в турбизнесе - из социальных сетей, медиа-СМИ, процессно- и проблемно-ориентированных площадок, SMS- и e-mail-рассылок, PR.

\section{Крау фан $\triangle и н г$ \\ и крау $\triangle е н \Delta и н г$ \\ в турбизнесе}

Токены ближе к облигациям, ICO - к краудфандингу. Самые известные краудфандинг-площадки Kickstarter, российские Boomstarter, Kroogi. Туроператоры работают с краудфандингом достаточно давно, но не системно, а на ниве развития отдельного сервиса (например, отельного, логистического). Многие крауд-платформы связаны с соцсетями, через аккаунты в соцсетях, что дает возможность отслеживать активность пользователей, сотрудничать с авторами проектов.

В России - несколько десятков краудфандинг-платформ, функционирующих как за счет комиссии, доли в бизнесе, так и путем морального удовлетворения.

Краудфандинг - вариант получения инвестиций туристическим стартапом, поддержка его, в основном, финансами. Он довольно распространён, многие туркомпании находятся в поисках средств реализации замыслов, не осваивая соответствующие площадки. Впервые определение «краудфандинг» появилось в 2006-м (Джефф Хауи). Дословно (crowd+funding) получится «финансирование народом, толпой». Кооперация людей, по своему желанию отдающих личные средства, чтобы посодействовать другим людям или даже предприятиям с интересным проектом.

Краудфандинг-платформа - специализированный, развитый портал, бизнес- и сервис-площадка идей, с определенной системой, структурой.

Чтобы краудфандинговый туристический проект стал успешен, необходимы:

1. четко сформулированная идея, туристическому стартаперу следует предоставить потенциальным вкладчикам актуальную и достаточно продуманную идею, которая их заинтересует;

2. ограничение по времени (время сбора денег должно быть ограниченным);

3. рекламные усилия (турбизнес-идею необходимо рекламировать и вне краудфандинг-платформы, хотя это оказывается неожиданным препятствием для туркомпаний);

4. ориентированность на результат (получивший финансирование обязан представить отчёт о достигнутых результатах и расходах или вернуть полученные средства);

5. разумный масштаб туристического проекта (не переоценивая свои возможности, начать с небольшого турбизнеса, понемногу осваиваясь, не взваливая на плечи непосильную ношу и разочаровываясь в данной сфере);

6. оригинальность (краудфандинг-идея туризма должна быть уникальной, выдержать конкуренцию);

7. открытость (больше полезной, актуальной и интересной информации о себе, бизнесе, турах, туризме - инвесторам выбрать вас будет легче и спокойней). 
Все перечисленное приносит плоды, если учесть, что никто не захочет финансировать неинтересные (непонятные) туристические проекты, максимально все должно быть прозрачно, информируемо. Хотите оригинальные туристические продукты - подробно распишите предполагаемые затраты и ожидаемую прибыль, составить аналог бизнес-плана для краудфандинг-платформы.

Нельзя считать, что если туристический проект вынесен на платформу краудфандинга, то посетители увидят его. Площадка отвечает только за накопление средств, перечисляемых людьми - самому предпринимателю нужно продвигать и раскручивать свой проект на других веб-страницах, в соцсетях и тур-блогах. Они просты для донесения мнений турбизнеса, достоинств турпродукта, рекламирования, активации маркетингового разнообразия (SMM, директ, аффилианты, инфлюенсер и др.), которое и становится толчком к упорядочиванию.

Держатель аккаунта становится «пособником» туркомпании, турпродукта за счет комментирования в группе продукта. Туроператор «отдает право рекламирования» продукта путешественникам, «замаскированным» под «социальных партнеров, одногруппников». Риски спама, мошенничества («скрывания за фото», инсайдерства, доверчивости «друзьям» («в группе - одни друзья») существуют. Поэтому интранет-сети туркомпаний стараются задействовать все свои корпоративные ресурсы, обеспечивая безопасность своих клиентов.

Популярна и краудлендинг-модель турбизнеса. Краудлендинг - платформа, объединяющая платежеспособных, не обремененных возвратом небольшого кредита (по ставке, даже больше банковской) инвесторов и соискателей инвестиций. Интересна перспектива криптовалютного займа. У криптовалюты больше функций (чем у традиционной), больше и шире возможности транзакций. Например, беспроблемные операции с «короткими (до \$10000) деньгами» с возвратом до 3-4 лет при ставке 7-8\%.

Краудлендинг-кредитование - аналог банка для физлиц, компаний от физлиц. Составляется заявка, и если параметры совпали, система автоматически обе стороны состыковывает. Затем очередь онлайн-договора со всеми тонкостям финансов. «Ручной» поиск не исключен.

Популярность краудлендинга обеспечивается:

1. невозможностью заемщику кредитоваться в банке (например, условия кредитования невыгодны);

2. непривлекательностью инвестиционных инструментов инвесторов, например, «Все включено» уже отменяется многими туркомпаниями;
3. поддержкой событийного, рекреационного туризма.

Краудлендинг способствует минимизации рисков, стимулируя долгосрочное финансирование. Проверяется тщательно личность, наличие задолженности, просрочек. Осуществляется автоинвестирование - без участия кредитора, достаточно указать критерии. Есть обоюдные границы максимума и минимума выдаваемых средств.

\section{Зак^ючение}

Активность турфирмы ведет к стабильности в «широком» смысле, по основным параметрам (оборачиваемость, задолженность, собственность и др.). Цифровые трансформации - везде, в туризме - также. Несмотря на сложности экономического регулирования, в туризме актуален переход к цифровой инфраструктуре, укрепление доверия клиентов и фирм. Турбизнес, понимая это, признает необходимость эволюции цифровых процессов.

В ближней перспективе туристическая отрасль сменит бизнес-модели, принципы эволюции, прорывные инновации цифровыми аналогами, снижающими издержки и позволяющими активироваться в глобальных каналах продаж, ликвидируя посреднические звенья (риски), например, бронирования, логистики и др.

Туризму потребуется автоматизация, интеллектуализация, особенно сейчас, когда много компаний, сервиса, трудоемких и ресурсоемких процессов. Операторы, агентства должны согласовываться по времени, параметрам, экономическим индикаторам для обеспечения высокого темпа оборачиваемости капитала, высокой отдачи инвестиций, снижения стоимости процессов при росте сервисных возможностей и корпоративной деятельности.

Методология блокчейн может нести дополнительную выгоду обществу, его финансовой системе, туркомпаниям. Криптовалюты активизируемы в турбизнесе без особых ресурсных вложений. Можно даже свою криптовалюту выпустить, если купить мощности или арендовать облачный майнинг (аналогично облачным вычислениям).

Но пока не заявлены принципиальные намерения. Власти пока ограничивать и регулировать блокчейн не желают. Криптовалюты активизируются в туристическом бизнесе, показывая существенный интерес бизнес-агентов. Впрочем, как и в России, власти многих стран советуют туркомпаниям лишь «тестирование» блокчейн. В том числе, для борьбы с коррупцией, мошенниками в среде блокчейн, выполняемых в ней функций. 


\section{ЛИТЕРАТУРА}

1. Ленчук Е.Б., Власкин Г.А. Формирование цифровой экономики в России: проблемы, риски, перспективы // Вестник Инст-та экономики РАН, 2018, № 5. C.9-21.

2. Богомазова И.В., Аноприева Е.В., Климова Т.Б. Цифровая экономика в индустрии туризма и гостеприимства: тенденции и перспективы // Сетевой научный журнал «СЕРВИС», 2019, т. 13, № 3(85). D01:10.24411/1995-042Х-2019-10303.

3. Морозов М.А., Морозова Н.С. Новая парадигма развития туризма и индустрии гостеприимства в условиях цифровой экономики // Вестник Российского нового университета (сер. «Человек и общество»), 2018, № 1. -С.135-141.

4. Глухова Л.В., Казиев В.М., Казиева Б.В. Повышение инвестиционной привлекательности региона: проблемы реализации приоритетных инновационных проектов. Сборник трудов «Прорывное развитие экономики России: условия, инструменты, эффекты» Международной конференции, 2018, кБГУ.—С.75-85.

5. Багдасарян В.Г. Цифровая экономика в индустрии туризма // Бизнес-образование в экономике знаний, 2020, № 2, с. 12-14.

6. Идрисов А. Лучшие мировые практики цифровой трансформации туристической деятельности [Электронный pecypc]. URL: http://digitalbusinessmodel.ru/ page7181064.html (дата обращения: 02.03.2021).

7. Климова Т.Б., Богомазова И.В., Аноприева Е.В. Шеринг-экономика в индустрии туризма и гостеприимства: новые тренды и тенденции // Научные ведомости БелГУ (сер. «Экономика. Информатика»), 2019, т. 47, № 2. -С.238-247.

8. Urquhart Ellis. Technological mediation in the future of experiential tourism. Special Iss. «The future of experiential travel» in Elsevier's J. of Tourism Futures, 2019. URL: https://www.emarketer.com/Report/GlobalDigital-Travel-Platforms-2017-Country-by-Country-Review-of-Top-Travel-Sites/2002133 (дата обращения: 22.02.2021).

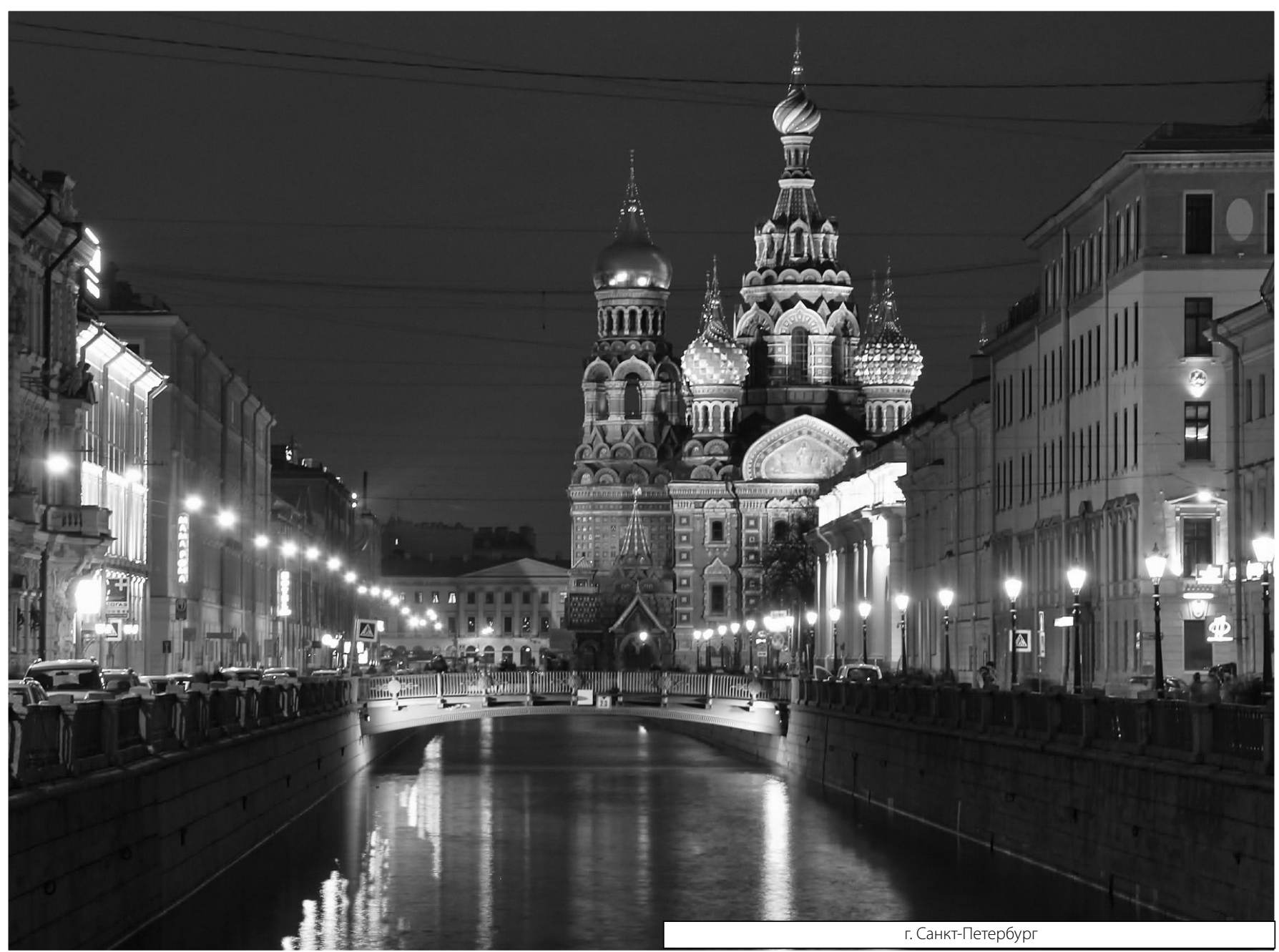

